\title{
Faisán S2016: nueva variedad de trigo harinero de gluten débil para El Bajío
}

\author{
Ernesto Solís Moya ${ }^{1 \S}$ \\ Luis Antonio Mariscal Amaro ${ }^{1}$ \\ Julio Huerta Espino ${ }^{2}$ \\ Héctor Eduardo Villaseñor Mir ${ }^{2}$ \\ Lourdes Ledesma Ramírez ${ }^{1}$ \\ Patricia Pérez Herrera ${ }^{2}$
}

${ }^{1}$ Campo Experimental Bajío-INIFAP. Celaya, Guanajuato, México. AP. 112. CP. 38010. Tel. 01800 0882222, ext. 85210. (mariscal.luis@inifap.gob.mx; lulis_amigui@ hotmail.com). ${ }^{2}$ Campo Experimental Valle de México-INIFAP. Carretera los Reyes-Texcoco km 13.5, Coatlinchán, Texcoco, Estado de México. CP. 56250. (huerta.julio@inifap.gob.mx; villasenor.hector@inifap.gob.mx). ${ }^{3}$ Tecnológico de MonterreyCampus Pachuca. Boulevard Felipe Ángeles núm. 2003, CP. 42080. (paty-pehe@ hotmail.com).

${ }^{\S}$ Autor para correspondencia: solis.ernesto@inifap.gob.mx.

\section{Resumen}

Faisán S2016 es una variedad de trigo suave cuya harina es útil para la industria galletera o para utilizarla en mezclas para mejorar trigos de gluten fuerte. Es moderadamente resistente a la roya amarilla y muestra gran estabilidad en un amplio rango de fechas de siembra y calendarios de riego. Su rendimiento superó en 16.8 y $18.6 \%$ a las variedades de trigos suaves Urbina S2007 y Maya S2007, liberadas en 2007 y hasta con $21 \%$ a Cortazar S94, la variedad más sembrada en El Bajío. obtuvo el título de obtentor, quedando protegida hasta el 18 de mayo de 2032; asimismo, está registrada y publicada en el catálogo nacional de variedades vegetales, con lo cual es posible considerarla en los programas de calificación y producción de semillas.

Palabras claves: eficiencia en el uso del agua, roya amarilla, secadera del trigo.

Recibido: septiembre de 2019

Aceptado: octubre de 2019 
De acuerdo con la ley de producción, certificación y comercio de semillas vigente en México, y después de haber reunido los requisitos que marca la Unión Internacional para la protección de las obtenciones vegetales (UPOV), la variedad Faisán S2016 obtuvo el título de obtentor 1699 quedando protegida en el catálogo nacional de variedades vegetales (CNVV) por parte de INIFAP hasta el 18 de mayo de 2032.

La variedad de trigo harinero Faisán S2016 es de hábito de primavera y fue obtenida en el Programa de Mejoramiento Genético de Trigo del INIFAP en el Campo Experimental Bajío (CEBAJ), por hibridación y selección; a través, del método de mejoramiento genético masal con selección, mediante una cruza entre los progenitores PASA/CUBA//CIRA/3/LOTH/GRACIA, cuyo número de cruza e historia de selección es TR05CS191-3C-0R-0C-2RSE-1CSE-0R.

Durante el proceso de selección la generación $\mathrm{F}_{1}$ se cosechó masalmente en Celaya, Guanajuato en la $\mathrm{F}_{2}$ la planta reconocida como 3C se trilló en forma individual en Texcoco, Estado de México, la $\mathrm{F}_{3}$ se cosechó masalmente en Celaya, Guanajuato en el ciclo otoño-invierno (OI) 2007-2008, en $\mathrm{F}_{4}$ se cosechó masalmente en Texcoco, Estado de México durante el verano 2008.

La generación F5 se sembró en Celaya, Guanajuato, en el ciclo OI 2008-2009 y se aplicó selección por espiga en las familias seleccionadas, en este caso la espiga identificada como 2RSE se avanzó como línea $\mathrm{F}_{6}$. En la generación $\mathrm{F}_{6}$ se aplicó selección por espiga en las familias seleccionadas, en este caso la espiga identificada como 1CSE se avanzó como línea $F_{7}$. Finalmente, en el ciclo OI 2009-2010 la generación $\mathrm{F}_{7}$ se cosechó masivamente en Celaya, Guanajuato, al no haber encontrado diferencias fenotípicas apreciables. A partir de 2010-2011 se empezó a evaluar en ensayos de rendimiento en el CEBAJ y en los ciclos 2013-2014, 2014-2015, 2015-2016 y 20162017 en diferentes localidades de la región de El Bajío.

La variedad Faisán S2016 es de hábito de crecimiento de primavera, semienana, de $92 \mathrm{~cm}$ de altura, su ciclo vegetativo es intermedio, con 78 días a floración y 132 días a madurez fisiológica. El tallo de la variedad Faisán S2016 es fuerte, hueco, de color crema y moderadamente resistente al acame. La espiga es de color claro, piramidal, con barbas y de longitud media. Generalmente produce tres granos por espiguilla en la base, cuatro en la parte media y tres en el ápice.

Las glumas son de color blanco, de pico corto, de forma ligeramente curva. La forma predominante del hombro es recta y de ancho medio. La extensión de la vellosidad interna de la gluma es débil. El grano es de color blanco, de forma ovoide, bordes redondeados y endospermo débil, con respuesta al fenol media.

La resistencia en plántula de Faisán S2016, fue determinada al inocular con 18 razas de roya de la hoja. En la variedad Faisán S2016, se postuló la presencia de 5 genes de resistencia en estado de plántula: Lr3, Lr13, 16, 17 y 23. De todos los genes de resistencia postulados, solo Lr16 es efectivo en plántula y confiere resistencia parcial en planta adulta. Lr3, 13, 17 y 23 no son efectivos en contra de las dos razas más comunes en México que son MBJ/SP y MCJ/SP.

En planta adulta, la resistencia de Faisán S2016 se basa en la acción de tres a cuatro genes de efecto aditivo. Uno de estos genes es el gen Lr46 localizado en el cromosoma 1BL e inicialmente identificado en la variedad Pavón F76 (William et al., 2003). Lr46 se ha asociado con la quemadura de la punta de la hoja (Rosewarne et al., 2006) y se determinó su presencia mediante el uso de un marcador molecular. Lr46 está presente en variedades como Salamanca S75 (Kolmer et al. 1998) y Alondra F2014 (Solís et al., 2016). 
La nueva variedad basa su resistencia a roya lineal en por lo menos tres genes de enroyamiento lento en planta adulta (Singh et al. 2001), uno de ellos el gen Yr29 ligado al gen de roya de la hoja Lr46 (William et al. 2003) y también asociado con la quemadura de la punta de la hoja (Rosewarne et al., 2006) y el segundo es Yr30 ligado al gen de resistencia para roya del tallo Sr2 (Singh et al., 2005).

La variedad Faisán S2016 tuvo una resistencia moderada a la secadera del trigo por el hongo Fusarium proliferatum, el daño en la raíz no sobrepasó 25\%, en cambio, Urbina S2007 obtuvo hasta 50\% de infección en la raíz, para la pudrición de la corona ocasionada por este mismo hongo Faisán S2016 alcanzó hasta 27\% de infección mientras que Urbina S2007 presentó 44\%.

En regiones productoras de trigo en donde se tengan problemas con la secadera del trigo se recomienda complementar la siembra de Faisán S2016 con un tratamiento a la semilla utilizando ya sea el fungicida Carboxim + Thiram $\left(\operatorname{Vitavax}^{\circledR}\right.$ ) a dosis de $250 \mathrm{~mL}$ en $100 \mathrm{~kg}$ de semilla o Clorotalonil a dosis de $250 \mathrm{~g}$ en $100 \mathrm{~kg}$ de semilla.

El rendimiento potencial de Faisán S2016 es superior a $9 \mathrm{t} \mathrm{ha}^{-1}$, su periodo óptimo de siembra es del 1 al 15 de diciembre, aunque se sugiere sembrarla del 16 de noviembre al 31 de diciembre, aún puede sembrarse en enero donde supera a todas las variedades comerciales.

Al comparar en fechas de siembra el rendimiento promedio de Faisán S2016 con el obtenido por las variedades recomendadas para El Bajío, durante los ciclos otoño invierno 2013-2014 a 20162017 se observó que la nueva variedad superó a Eneida F94 con 41.3\%, a Luminaria F2012 con $31.8 \%$, a Salamanca S75 con 28.1\%; a Bárcenas S2002 con 17.5\%; a Cortazar S94 con 17.3\%, a Maya S2007 con $15.7 \%$; a Urbina S2002 con $14.4 \%$ y a Alondra F2014 con $7.5 \%$, su rendimiento fue superior a cualquier variedad tanto en fechas de siembra tempranas como tardías.

En evaluaciones bajo riego restringido, con dos riegos obtuvo rendimiento de $5831 \mathrm{~kg} \mathrm{ha}^{-1}$, superior $1.2 \%$ a la variedad comercial de mayor potencial de rendimiento (Alondra F2014) y 18.5\% a la variedad Cortazar S94 la más extensamente sembrada en El Bajío. Con tres riegos obtuvo un rendimiento de $7018 \mathrm{~kg} \mathrm{ha}^{-1}, 7$ y $14.1 \%$ superior a Alondra F2014 y Cortazar S94, respectivamente. Faisán S2016 se evaluó en 14 localidades del Bajío en los ciclos 2013-2014 a 2016-2017, en estas pruebas superó el rendimiento de Urbina S2007, Bárcenas S2002, Cortazar S94, Alondra F2014, Maya S2007, Salamanca S75 y Luminaria F2012 con 7, 5.3, 13.1, 5.3, 9.3, 13.3 y 19.8\%, respectivamente.

La nueva variedad de trigo Faisán S2016, al igual que las variedades Urbina S2007 y Bárcenas S2002 es de grano blanco. El peso hectolítrico promedio de Faisán S2016 (77.5) es superior en 2 a $3.8 \mathrm{~kg} \mathrm{hL}^{-1}$ al de las variedades testigo Maya S2007, Bárcenas S2002 y Urbina S2007. El grano de Faisán S2016 es suave, de acuerdo con su índice de perlado promedio, superior al 60\%. Faisán S2016 presenta un contenido de proteína en grano promedio (12.3\%), similar al de la variedad testigo Bárcenas S2002 (12.5\%) y menor en 0.6 a $0.8 \%$ al de las variedades Maya S2007 (12.9\%) y Urbina S2007 (13.1\%), respectivamente.

Las masas obtenidas a partir de las harinas de Faisán S2016, presentaron una fuerza de gluten promedio (W) de $150 \times 10^{-4} \mathrm{~J}$, que permite caracterizarla como un trigo de gluten débil, condición consistente con la suavidad del grano. La fuerza del gluten promedio de Faisán S2016 fue menor 
que el de las variedades testigo Urbina S2007, Maya S2007 y Bárcenas S2002 (W de160 a 192 x $\left.10^{-4} \mathrm{~J}\right)$. La fuerza de gluten de Faisán S2016, se ubicó en los valores correspondientes a los trigos de gluten débil ( $\mathrm{W}<200 \times 10^{-4} \mathrm{~J}$ ). Faisán S2016 presentó un valor promedio de índice P/L de 1, que corresponde a un gluten balanceado; mientras que las variedades testigo de gluten débil: Urbina S2007, Maya S2007 y Bárcenas S2002, presentaron gluten extensible (P/L de 0.5 a 0.7).

El factor galletero de la variedad Faisán S2016 fue semejante al de la variedad testigo Maya S2007, pero menor al de las variedades testigo: Urbina S2007 y Bárcenas S2002. A pesar de lo anterior, los factores galleteros de la nueva variedad de trigo suave Faisán S2016 y las tres variedades testigo, correspondieron a la calificación de 'muy buena calidad galletera'. Por ello, la nueva variedad de trigo suave Faisán S2016 tiene las características de calidad de harina adecuadas para su utilización en la elaboración de galletas. Faisán S2016 presenta GAPM en donde predominan las subunidades Glu A1 2*, Glu B1 7+9 y Glu D1 2+12, que se han asociado a trigos de gluten débil, que presentan una fuerza de masa adecuada para la elaboración de galletas (Martínez et al., 2013).

La nueva variedad de trigo suave Faisán S2016 presenta parámetros de calidad comercial que aseguran su competitividad en el mercado, calidad industrial que asegura su aptitud para ser empleada en la elaboración de productos que demandan como materia prima harinas de gluten débil y finalmente, propiedades de fuerza y extensibilidad del gluten que favorecen su empleo como mejorador de harinas de gluten fuerte tenaz.

La nueva variedad Faisán S2016 se recomienda para la región de El Bajío, la cual comprende parte de los estados de Guanajuato, Michoacán, Jalisco y Querétaro, con alturas de 1500 a 1800 msnm, temperatura media de $20{ }^{\circ} \mathrm{C}$ y precipitación de 450 a $650 \mathrm{~mm}$. La semilla básica de Faisán S2016 está disponible en el INIFAP- Campo Experimental Bajío para su venta a las compañías productoras de semilla que lo soliciten desde diciembre de 2017.

\section{Conclusiones}

La variedad Faisán S2016 superó el rendimiento de las variedades comerciales actualmente en uso en ensayos en fechas de siembra, es más eficiente en el uso del agua, moderadamente resistente a roya lineal amarilla y de la hoja, es más resistente a la secadera del trigo y su calidad galletera es similar a la de las variedades de gluten débil.

\section{Agradecimientos}

Al Grupo Bimbo SA de CV, por el financiamiento del proyecto 'mejoramiento genético para la obtención de variedades de trigo de gluten fuerte y débil con alta calidad industrial, para la región del Bajío, México'. Asimismo, al CONACYT por el financiamiento al proyecto CONACYT-SAGARPA-COFUPRO 'Sistema de mejoramiento genético para generar variedades de trigo resistentes a royas, de alto rendimiento y alta calidad para una producción sustentable en México’. 


\section{Literatura citada}

Kolmer, J. A. 1998. Physiologic specialization of Puccinia recondita f. sp. tritici in Canada in 1996. Canadian J. Plant Pathol. 20(2):176-81.

Martínez, C. E.; Espitia, E. R.; Villaseñor, M. H. E.; Hortelano, R. S.; Rodríguez, M. F. G. y Peña, R. J. B. 2013. Las combinaciones de gluteninas de los loci Glu-1 y Glu-3 y la calidad de la masa de trigo harinero Rev. Mex. Cienc. Agríc. 4(8):1139-1149.

Rosewarne, G. M.; Singh, R. P; Huerta-Espino, J.; William, H. M.; Bouchet, S.; Cloutier, S.; McFadden H. and Lagudah, E. S. 2006. Leaf tip necrosis, molecular markers and 1proteasome subunits associated with the slow rusting resistance genes Lr46/Yr29. Theor. Appl. Genet. 112(3):500-508.

Singh, R. P.; Huerta, J. E. and William H. M. 2001. Resistencia durable a roya de la hoja y roya amarilla del trigo. In: estrategias y metodologías utilizadas en el mejoramiento de trigo un enfoque multidiciplinario. Man, M. K.; Díaz, A. M. and Castro, M. (Eds.). La estanzuela Uruguay 8-11 de octubre. 109-117 pp.

Singh, R. P.; Huerta-Espino, J. and William M. 2005. Genetics and breeding for durable resistance to leaf and stripe rust in wheat. Turk. J. Agric. For. 29(2):121-127.

Solís-Moya, E.; Huerta-Espino J.; Pérez-Herrera, P.; Villaseñor-Mir, H. E.; Ramírez-Ramírez, A. y De La Cruz-González, M. L. 2016. Alondra F 2014: nueva variedad de trigo harinero para el Bajío, México. Mex. Cienc. Agríc. 7(5):1225-1229.

William, M.; Singh, R. P.; Huerta-Espino, J.; Ortiz- Islas, S. and Hoisington, D. 2003. Molecular marker mapping of leaf rust resistance gene Lr46 and its association with stripe rust resistance gene Yr29 in wheat. Phytopathology. 93(2):153-159. 